\title{
SISTEMA ELEITORAL E REELEIÇÃO NAS ELEIÇÕES MUNICIPAIS DE 2012 PARA O EXECUTIVO NO BRASIL ${ }^{1}$
}

Bruno da Silva Conceição ${ }^{2}$

\begin{abstract}
Resumo
Neste artigo investigamos o efeito do sistema eleitoral na competição municipal para o cargo de Prefeito na eleição de 2012. A pesquisa questiona-se acerca das implicações teóricas das Leis de Duverger que apontam uma relação causal entre a fórmula eleitoral e a competição eleitoral. Utilizamos o conceito de competição eleitoral que corresponde ao número de candidatos efetivos concorrendo em cada pleito. Para medir isso, recorremos ao número de candidatos efetivos (NCE), índice que estabelece o número real de candidaturas que tem peso em uma disputa eleitoral. Nosso questionamento norteador é saber se haveria diferenciação na competição política nas cidades com turno único que utilizam a fórmula de Plurality (Maioria simples), comparada com aquelas cidades que possuem a possibilidade de segundo turno que utilizam a fórmula de Majority Runoff (maioria absoluta). Ainda inserimos uma segunda variável de controle que é o fator da reeleição. Nosso objetivo é testar se as Leis de Duverger perdem valor explicativo com a presença do Incumbent (Titular do Executivo municipal buscando a reeleição). Essa tarefa foi realizada pela análise comparada das competições municipais de 2012, em todas as cidades brasileiras, através dos dados provenientes do Tribunal Superior Eleitoral (TSE). Concluímos que a Plurality contribui para a redução da competição eleitoral nos municípios brasileiros e que o fator da reeleição afeta pouco o lançamento de candidaturas.
\end{abstract}

Palavras-chave: Sistema Eleitoral; Reeleição; Eleições 2012; Competição Eleitoral.

\begin{abstract}
In this article we investigate the effect of the electoral system in municipal competition for the position of mayor in the 2012 election. The research was questioned about the theoretical implications of Duverger laws that link a causal relationship between the electoral formula and electoral competition. We use the concept of electoral competition that is the number of effective candidates running in each election. To measure this, we use the number of effective candidates (NEC), used to establish the actual number of applications that have weight in an electoral contest. Our guiding question is whether there would be differentiation in competition policy in cities with single shift using the formula of Plurality, compared to those cities that have the possibility of runoff using the formula Majority Runoff. Even we insert a second control variable which is the re-election factor. Our goal is to test whether Duverger laws lose explanatory value with the presence of the Incumbent (municipal executive Holder seeking re-election). This task was performed by comparison of the municipal competitions of 2012, in all Brazilian cities, using data from the Supreme Electoral Tribunal (TSE). We conclude that the Plurality contributes to the reduction of electoral competition in Brazilian municipalities and the re-election factor affects just launching applications.
\end{abstract}

Keywords: Electoral System; Re-election; Elections 2012; Electoral Competition.

\section{Resumen}

En este artículo se investiga el efecto del sistema electoral en la competencia municipal para el cargo de alcalde en las elecciones de 2012. La investigación pregunta sobre las implicaciones teóricas de las leyes de Duverger que enlazan una relación causal entre la fórmula electoral y la competencia electoral. Utilizamos el concepto de la competencia electoral que es el número de candidatos eficaces que se ejecutan en cada elección. Para medir esto, utilizamos el número de candidatos eficaces (NCE), que se utiliza para establecer el número real de las aplicaciones que tienen peso en una contienda electoral. Nuestra pregunta guía es si habría diferenciación en la competencia política en las ciudades con un solo turno usando la fórmula de mayoría simple, en comparación con aquellas ciudades que tienen la posibilidad de escorrentía mediante la escorrentía fórmula de la mayoría absoluta. Incluso insertamos

\footnotetext{
${ }^{1}$ DOI deste artigo: 10.5380/recp.v6i1.39691.

2 Doutorando em Ciência Política da Universidade Federal do Rio Grande do Sul (UFRGS). E-mail: brunopolitica@gmail.com
} 
una segunda variable de control, que es el factor de la reelección. Nuestro objetivo es poner a prueba si las leyes de Duverger pierden valor explicativo con la presencia del Incumbent (Titular ejecutivo municipal busca la reelección). Esta tarea se llevó a cabo mediante la comparación de las competencias municipales de 2012, en todas las ciudades brasileñas, utilizando datos del Tribunal Supremo Electoral (TSE). Llegamos a la conclusión de que la pluralidad contribuye a la reducción de la competencia electoral en los municipios brasileños y el factor de reelección poco afecta a la liberación de aplicaciones.

Palabras-clave: Sistema Electoral; Reelección; Elecciones 2012; La competencia electoral.

\section{INTRODUÇÃO}

A agenda de reforma política vem sendo inserida há muito tempo no debate político do país, em virtude da "crise de representação" que afetaria a democracia brasileira. No entanto, existe uma falta de entendimento da população, e também em boa parte da opinião pública, acerca do funcionamento das instituições democráticas e do comportamento político nas eleições. A recorrente falta de conectividade entre eleitor e governante propagada a torto e direito como "crise da representação" - acentua a visão de que há uma pane na democracia representativa brasileira e, ademais, de que ela não funcionaria como deveria. Será mesmo?

Há uma confusão entre expectativas da população em distintos planos da representação. Sabendo que o sistema de representação proporcional tende a ser mais representativo dos grupos em conflito na sociedade, sendo aplicada para composição das cadeiras no Legislativo, a expectativa criada em torno das eleições majoritárias, de criarem vínculos entre representantes e representados, é errônea logo que o princípio dessa representação não é espelhar a sociedade, e sim, formar governo (NOHLEN, 1995). Desse modo, o distanciamento entre representante e representado, nas eleições ao Executivo, pode ser revisto através do conhecimento do sistema eleitoral.

No campo de pesquisa institucionalista, a obra "Os Partidos Políticos"3 teve grande relevância nos estudos posteriores à sua publicação. O cientista político Maurice Duverger estabeleceu nesse livro várias agendas de pesquisa na disciplina em razão da diversidade de temáticas encontradas nessa obra, que perpassam desde a origem dos partidos políticos modernos até uma explicação sobre o modelo organizativo dos partidos, além de um arcabouço teórico sobre o número de partidos políticos nos sistemas partidários ao mostrar que o sistema eleitoral vigente pode produzir ora um sistema bipartidário, ora um sistema multipartidário (DUVERGER, 1970).

Neste artigo opto por trabalhar com esta temática tradicional da Ciência Política. Esta pesquisa questiona-se acerca das implicações teóricas das Leis de Duverger sobre o

\footnotetext{
${ }^{3}$ Esta obra de Maurice Duverger foi publicada originalmente em 1951.
} 
número de competidores. Aplico ao cenário brasileiro as proposições das Leis de Duveger que apontam uma relação causal entre o sistema eleitoral e a competição eleitoral. Recorro como fonte de dados, para estabelecer tal relação de causalidade, os resultados das eleições municipais no ano de 2012 oriundos de estatísticas eleitorais disponíveis no site do Tribunal Superior Eleitoral (TSE).

As hipóteses estabelecidas aqui, derivadas das proposições de Maurice Duverger, são as seguintes: quando utilizada a fórmula eleitoral de plurality (maioria simples) há uma tendência ao dualismo de forças entre candidaturas; por outro lado, quando utilizada a fórmula de majority runoff (maioria absoluta) há um aumento na competição eleitoral com, pelo menos, mais de duas candidaturas devido a possibilidade do segundo turno eleitoral. Desse modo, as competições aos cargos majoritários no Brasil estariam condicionadas pela fórmula eleitoral adotada em cada pleito? Em resumo, as Leis de Duverger ajudam a explicar a competição política municipal?

Além disso, incluo uma segunda variável independente de controle relacionada à estrutura do sistema eleitoral: a possibilidade de reeleição. A intenção é testar a força explicativa das Leis de Duverger com a presença do Incumbent - Titular do Executivo municipal buscando a reeleição - desejando averiguar se há uma interação entre ambas as hipóteses. Esta última hipótese se baseia nos resultados de pesquisas recentes que apontam as altas chances de sucesso de reeleição em disputas em nível municipal ${ }^{4}$. Desta forma, este dado poderia ser revertido em estratégia para as lideranças políticas. Assim, talvez tenhamos uma diminuição de candidaturas quando o atual prefeito se candidata à reeleição e, de outro lado, um aumento de candidaturas quando este não o faz.

Após essa exposição sucinta dos objetivos do trabalho e das hipóteses a serem testadas, sigo com o roteiro da pesquisa. Na primeira parte, faço uma breve revisão da literatura acerca do sistema eleitoral e da sua influência na competição política e, também, uma descrição da metodologia a ser utilizada. Ao final, apresento a análise dos dados do número de candidatos efetivos, conforme a fórmula eleitoral e da presença do Incumbent, em todos os municípios brasileiros em 2012. Por último, apresento as considerações finais da pesquisa.

\footnotetext{
4 Álvaro Barreto (UFPEL) tem feito pesquisas recentes acerca da taxa de sucesso do Incumbent nas eleições subnacionais no Brasil e no Uruguai.
} 


\section{O CAMPO DE PESQUISA SOBRE O SISTEMA ELEITORAL}

A área de estudos sobre sistema eleitoral é prolífera em trabalhos que almejam relacionar os efeitos das regras eleitorais nos sistemas partidários (NOHLEN, 1995; NICOLAU, 1996; LIMA JR, 1997; TAVARES, 1997; COX, 1997; MAINWARING, 2001; LIJPHART, 2008; MARENCO, 2012, CONCEIÇÃO, 2014). No pano de fundo destas pesquisas está a discussão da validade teórica das famosas proposições aventadas por Maurice Duverger (1970). As Leis de Duverger são muito questionadas e testadas acerca de sua validade heurística. Elas enunciam que:

1. A representação proporcional tende ao multipartidarismo;

2. O sistema majoritário de dois turnos (Majority Runoff ou maioria absoluta) tende ao multipartidarismo;

3. O sistema majoritário de turno único (Plurality ou maioria simples) tende ao dualismo de partidos.

O enfrentamento empírico dessas "leis" aconteceu em duas vertentes. Primeiramente, com um foco no Legislativo baseado em análises voltadas para o cálculo do número de partidos efetivos (NEP) nas Assembleias Nacionais, percebendo os efeitos da configuração partidária com a adoção da plurality em distritos uninominais tenderem para um bipartidarismo, e, de outro lado, da representação proporcional em distritos plurinominais favorecer um multipartidarismo. A segunda vertente está direcionada para as eleições majoritárias, principalmente presidenciais, buscando testar os efeitos da competição eleitoral com maioria simples ou maioria absoluta. Este estudo incorpora-se nessa última vertente.

A competição eleitoral, aqui entendida, está pautada na forma de disputa da classe política, inseridos no modo de seleção de governantes da democracia representativa, que buscam a prevalência do voto popular para controlar o aparato público (SCHUMPETER, 1961). Assim, o conceito de competição eleitoral está conectado a luta intraelites políticas que devem se adaptar as regras eleitorais na busca dos cargos públicos.

Tais regras podem favorecer grandes partidos propiciando a manutenção do status quo político, ou ainda serem mais permissivas permitindo que novos competidores adentrem na arena eleitoral. Essa balança inclusiva ou exclusiva depende da percepção que as lideranças partidárias possuem do sistema eleitoral. Matthew Shugart e John Carey (1992) afirmam que a diferença básica entre a fórmula de plurality (maioria simples) e a fórmula de majority runoff (maioria absoluta) para a ação das lideranças partidárias é o timing que são feitas as barganhas políticas.

To maximize their chances of victory, party leaders contesting a plurality presidential election in a multiparty environment must seek to build coalitions 
before the election. In most cases this means that the principal contenders will be two relatively moderate candidates. On the other hand, because majority runoff leaves much of the bargaining among parties to the period between rounds, the efficiency of presidential election is reduced. (SHUGART and CAREY, 1992, p.216).

Essa percepção das chances de sucesso conforme a fórmula eleitoral vigente pode passar despercebida na maioria dos pequenos partidos. Continuam existindo partidos lançando candidaturas em contextos menos favoráveis de sucesso. Os custos dessa falta de informação do timing correto de levar em frente uma candidatura acarretam em perda de espaço posterior na formação das coalizões de governo. É provável que partidos que aderem mais cedo a um competidor vencedor terão uma maior fatia no "bolo" do governo, seja em postos da administração pública ou cargos comissionados.

Antes de partir para uma discussão sobre as hipóteses dessa pesquisa são necessários alguns apontamentos sobre a crítica da consistência da abordagem do sistema eleitoral influenciar o subsistema partidário. Alguns autores abordam uma inversão na direção da causalidade, estando o sistema partidário a influenciar o sistema eleitoral já que é a classe política quem determina as "regras do jogo" (COLOMER, 2003). Desse modo, um recorte que investigue as negociações interpartidárias feitas pelas lideranças políticas das siglas seria mais prolífero em explicações sobre como funciona a democracia representativa, restando ao sistema eleitoral o papel de consolidar as diretrizes feitas pela elite política.

Gary Cox (1997) aponta que apesar da incerteza da direção da causalidade, quem influencia quem, é nítido para o sucesso das lideranças partidárias coordenarem suas estratégias de maximização de sufrágios, ou mesmo ganhos políticos materiais, saber adaptarem-se as regras eleitorais existentes para seu benefício. Nessa perspectiva, conhecer o timing certo de lançar uma candidatura, desistir dela, ou fazer uma coalizão torna-se um requisito indispensável para o sucesso eleitoral.

\section{AS LEIS DE DUVERGER E O FATOR DA REELEIÇÃO}

As Leis de Duverger, principalmente as duas leis com enfoque para os efeitos do sistema eleitoral na competição política ao Executivo, são de interesse especial para a análise desta pesquisa. A primeira delas aborda que quando há um escrutínio majoritário de turno único, as legendas teriam reduzidas as expectativas de sucesso no pleito, pela regra da maioria simples para aprovação de um novo governo, tendendo na prática ao bipartidarismo: "Os métodos de maioria simples (plurality) em distrito uninominal são do tipo 'o vencedor leva tudo': vencem os candidatos apoiados pelo maior número de eleitores, e todos os demais 
ficam sem representante - o que reflete perfeitamente a filosofia majoritária." (LIJPHART, 2008, p.169). O exemplo típico é o bipartidarismo norte-americano que, através de suas regras eleitorais, termina por limitar a disputa entre o Partido Republicano e o Partido Democrata.

O efeito derivado do sistema majoritário de turno único produz dois tipos de fatores: o fator mecânico que amparado na regra eleitoral força uma sub-representação da terceira força política, e o fator psicológico, atuando no eleitor, que retira votos dessa terceira força politica. Os fatores mecânicos e psicológicos beneficiam os grandes partidos ao induzirem os eleitores, pelo temor de desperdiçar seu voto, a selecionarem sua segunda candidatura preferencial, com reais chances de sucesso no pleito, como opção na cabine de votação (DUVERGER, 1970).

Sobre a segunda lei de Duverger analisada aqui neste estudo, temos uma lógica inversa. Quando há um escrutínio majoritário de dois turnos tende-se a um aumento dos competidores, logo que há uma primeira rodada de classificação, de duas candidaturas, para uma posterior rodada final. "De fato, a ação do sistema de escrutínio poderia ser comparado à de um freio ou de um acelerador" (DUVERGER, 1970, p.241). Apenas quando não temos um franco favorito, que vença já no primeiro turno, prospera um cenário de incerteza sobre quem passará para o segundo turno incentivando o lançamento de candidaturas.

$\mathrm{Na}$ ótica dos partidos, eles necessitam posicionar-se conforme as regras do jogo de maneira pragmática no intuito de maximizar suas chances de arrecadação de sufrágios (COX, 1997; DOWNS, 1999). Os candidatos teriam incentivos, na volta inicial, para apresentarem seus programas partidários, suas posições no que tange assuntos cotidianos ou problemas frequentes do município, etc. Sedimentados os postulantes ao cargo do Executivo, na rodada final interessa cativar seu projeto no imaginário da população. Aqueles com uma vantagem adquirida na primeira volta tentam manter sua votação, enquanto os segundos colocados almejam uma ultrapassagem final, recolhendo os votos restantes dos perdedores da rodada inicial.

A outra variável independente a ser testada é a influência do dispositivo da reeleição na teoria institucionalista de Duverger (1970). Alguns estudos apontam que o fato do Incumbent - Titular do Executivo municipal buscando a reeleição - participar da eleição, acarreta em altas taxas de sucesso para o mesmo. (ARENAS y VALENCIA, 2009; CARDARELLO, 2009; BARRETO, 2012; BARRETO, 2014). Esta variável institucional também foi inserida na pesquisa pelos ganhos que o candidato à reeleição possui frente aos seus adversários, pois dispõe de maior acesso a exposição midiática, possivelmente mais 
recursos para financiamento de campanhas, além dos recursos da máquina pública (CARDARELO, 2009).

Sendo também a disputa municipal uma prestação de contas do mandato, a presença do Incumbent no pleito torna a competição num plebiscito de aceitação ou reprovação do atual Prefeito concorrendo à reeleição (CARDARELLO, 2009; BARRETO, 2014). Questiono se essa possibilidade de reeleição imediata, não prevista no modelo de Duverger (1970), acarreta em perda do valor explicativo de suas leis. Nesse intuito, recolho os dados dos prefeitos eleitos na eleição de 2008, esses sendo eleitos pela primeira vez, com os resultados eleitorais dos candidatos que podiam concorrer para uma reeleição imediata na eleição de 2012, na intenção de medir se o fator da presença do Incumbent afeta, ou não, a competição eleitoral.

\section{METODOLOGIA}

A metodologia adotada nesta pesquisa será separar os municípios com segundo turno daquelas localidades de turno único para analisar os efeitos das leis de Duverger quanto à fórmula eleitoral: Plurality (maioria simples) e Majority Runoff (maioria absoluta). O teste da consistência das leis de Duverger será através de um índice amplamente utilizado na Ciência Política. Para tanto, não utilizo o número de partidos concorrentes, mas sim pela identificação do Número de Candidatos Efetivos (NCE), extraído da seguinte fórmula:

\section{$\mathrm{N}=1 / \sum(\mathrm{Vi} / 100)^{2}$}

Onde: $\mathrm{Vi}=$ percentagem de votos de cada candidato

A substituição do foco de pesquisa dos partidos para, no seu lugar, a análise das candidaturas $^{5}$ ao Executivo municipal torna-se o caminho teórico mais viável para mensurar a competição municipal ao Executivo (SHUGART \& CAREY, 1992; COX, 1997). Com base neste índice de candidatos efetivos (NCE), estabeleço que valores de 1,5 a 2,5 indicam uma disputa condensada em um dualismo, ou seja, esses valores representam que apenas duas

\footnotetext{
${ }^{5}$ Cox (1997) utiliza a nomenclatura Number of Viable Competitors para analisar a competição eleitoral nas eleições majoritárias. É usada a fórmula de índice de número de partidos efetivos de Laakso e Taagepera (1979) aplicando o cálculo à percentagem de votos dos candidatos ao posto de Prefeito.
} 
candidaturas possuem potencial de sucesso. Isto será nomeado neste artigo como bicandidaturas.

Já os valores do (NCE) acima de 2,5 denotam uma competição com mais de dois candidatos sendo nomeada como multicandidaturas. Como última observação, aponto que os valores de candidatos efetivos abaixo de 1,5 foram incorporados aos resultados de bicandidaturas devido à ocorrência de poucos casos com valores inferiores a 1,5. E também por se enquadrarem dentro da tendência prevista por Duverger (1970) de diminuição da competição eleitoral.

\section{ANÁLISE DOS DADOS DAS ELEIÇÕES MAJORITÁRIAS DE 2012}

Parto neste instante para uma análise detalhada do objeto de pesquisa. Vale relembrar que as hipóteses de pesquisa seguem duas direções: a fórmula eleitoral de Plurality (maioria simples) tenderia ao dualismo de forças entre candidaturas; por outro lado, a fórmula eleitoral de Majority Runoff (maioria absoluta) tenderia há um aumento na competição eleitoral com, pelo menos, mais de duas candidaturas.

Abaixo, na tabela 1 , mostro o cruzamento da fórmula eleitoral (variável independente) produzindo efeitos na competição eleitoral (variável dependente). Nesta primeira tabela temos $41 \%$ de diferença na competição entre bicandidaturas conforme a fórmula vigente, e uma diferença de $41 \%$ nas multicandidaturas conforme a fórmula eleitoral utilizada. Isto demonstra que as hipóteses de pesquisa, ancoradas nas Leis de Duverger, têm um grande valor explicativo para compreendermos o número de competidores, ao cargo de chefe do executivo municipal em 2012, já que a predição teórica de diminuição da competição em Plurality e aumento desta em Majority Runoff é significativa em termos percentuais.

Tabela 1-Competição eleitoral nos municípios brasileiros em 2012 conforme a fórmula eleitoral

\begin{tabular}{c|c|c}
\multicolumn{2}{c}{$(\%)$} \\
\cline { 2 - 3 } Competição Eleitoral & Plurality & Mórmula Eleitoral \\
\cline { 2 - 3 } & 85 & 44 \\
\hline Bicandidaturas & 15 & 56 \\
\hline Multicandidaturas & \multicolumn{2}{|c}{ Runoff } \\
\hline
\end{tabular}

Fonte: TSE, dados processados pelo autor. $\mathrm{N}=5556$.

Nas duas próximas tabelas, apresento os dados desagregados por região (Norte, Nordeste, Centro-Oeste, Sudeste e Sul) e por fórmula eleitoral. Na tabela 2, a média percentual da soma de resultados de bicandidaturas nas regiões brasileiras em 2012 chegou a $82 \%$. Os dados verificados nos municípios brasileiros são representativos dos efeitos 
redutores da competitividade eleitoral, quando não há a possibilidade do segundo turno, com a sub-representação das pequenas candidaturas em favor dos dois candidatos mais bem posicionados conhecida como fator mecânico. "Riker's analysis confirms that the link between two-party systems and plurality voting has been observed and verified for a longer time than the others". (DUVERGER, 2003, p.70).

Tabela 2 - Competição eleitoral nos Municípios por Região com Plurality nas eleições de primeiro turno de $2012(\%)$

\begin{tabular}{|c|c|c|c|c|c|c|}
\hline \multirow[b]{2}{*}{ Plurality } & \multicolumn{5}{|c|}{ Regiões do Brasil } & \multirow[b]{2}{*}{ Total } \\
\hline & $\begin{array}{l}\text { Região } \\
\text { Norte }\end{array}$ & $\begin{array}{c}\text { Região } \\
\text { Nordeste }\end{array}$ & $\begin{array}{c}\text { Região } \\
\text { Centro-Oeste }\end{array}$ & $\begin{array}{l}\text { Região } \\
\text { Sudeste }\end{array}$ & $\begin{array}{c}\text { Região } \\
\text { Sul }\end{array}$ & \\
\hline Bicandidaturas & 70 & 89 & 83 & 82 & 89 & 85 \\
\hline Multicandidaturas & 30 & 11 & 17 & 18 & 11 & 15 \\
\hline Total & $(442)$ & $(1775)$ & $(457)$ & $(1620)$ & $(1179)$ & 100 \\
\hline
\end{tabular}

Fonte: TSE, dados processados pelo autor. $\mathrm{N}=5473$.

Nessa situação, a solução das lideranças partidárias dos partidos pequenos para participarem da corrida ao governo será estabelecer pactos, alianças ou coligações antes do pleito já que os benefícios da entrada no governo após a eleição podem ser menores, resultando em influência diminuta em cargos ou ações do governo (SHUGART; CAREY, 1992).

Assinalado por Duverger (1970) como fator psicológico, ele é denominado de maneira diferente por Cox (1997) como voto estratégico, o recurso do voto útil atua para diminuir os custos do eleitor "desperdiçar" sua escolha em um candidato com poucas chances de sucesso, escolhendo alguém mais bem posicionado nas pesquisas. Isso acarreta que o processo de competição dentro do mercado eleitoral é limitado tanto pela imposição endógena da fórmula eleitoral, quanto pela dificuldade de arrecadar investimentos para campanha nestas cidades. Apesar dos esforços da Justiça Eleitoral brasileira em fornecer espaço horizontal de exposição para as legendas no período de campanha, as discrepâncias em tempo de TV, em utilização de recursos provindos do fundo partidário e em aplicação dos gastos em marketing, são empecilhos substanciais para demarcar as barreiras que os pequenos partidos enfrentam para concorrer na corrida eleitoral contra seus adversários e os fatores mecânicos e psicológicos.

Conforme observou Cox (1997), o eleitorado que possua uma razoável informação sobre as preferências dos outros eleitores e do provável resultado final da eleição, informado pelos meios de comunicação e institutos de pesquisa, irá desistir do seu candidato preferido, 
se esse estiver posicionado em $3^{\circ}$ lugar, para sua segunda melhor opção dentre os líderes da disputa em Plurality. Então, esse conjunto de fatores, acima expostos, colabora para uma forte concentração da competição numa lógica dualista em distritos uninominais de turno único.

Neste instante, parto para os resultados eleitorais nas localidades que podem proceder numa segunda rodada de disputa. Assim, é possível comparar se os efeitos vistos em Plurality, os efeitos mecânico e psicológico que reduzem o número efetivo de candidatos em um dualismo, acabam mesmo perdendo sua eficácia em Majority Runoff. Um pequeno detalhe é que a utilização da Majority Runoff, no contexto municipal brasileiro, só ocorre nas cidades que excedam 200 mil eleitores $^{6}$. Isso está escrito de maneira pormenorizada tanto na Constituição Federal ${ }^{7}$, quanto na Lei n ${ }^{\circ}$ 9.504, de 30 de setembro de $1997^{8}$, que estabelece normas para as eleições. $\mathrm{Na}$ tabela 3, observam-se os resultados da competição eleitoral, por região, com Majority Runoff.

Tabela 3 - Competição eleitoral nos Municípios por Região com Majority Runoff nas eleições de primeiro turno de $2012(\%)$

\begin{tabular}{|c|c|c|c|c|c|c|}
\hline \multirow[b]{2}{*}{ Majority Runoff } & \multicolumn{5}{|c|}{ Regiões do Brasil } & \multirow[b]{2}{*}{ Total } \\
\hline & $\begin{array}{r}\text { Região } \\
\text { Norte }\end{array}$ & $\begin{array}{c}\text { Região } \\
\text { Nordeste }\end{array}$ & $\begin{array}{c}\text { Região } \\
\text { Centro-Oeste }\end{array}$ & $\begin{array}{l}\text { Região } \\
\text { Sudeste }\end{array}$ & $\begin{array}{c}\text { Região } \\
\text { Sul }\end{array}$ & \\
\hline Bicandidaturas & 17 & 35,5 & 40 & 50 & 25 & 41 \\
\hline Multicandidaturas & 83 & 64,5 & 60 & 50 & 75 & 59 \\
\hline Total & (6) & (14) & (5) & (46) & (12) & 100 \\
\hline
\end{tabular}

Fonte: TSE, dados processados pelo autor. Cidades $\mathrm{N}=83$.

\footnotetext{
${ }^{6}$ Jairo Nicolau (1996) aponta que os dois turnos foram incluídos na eleição presidencial devido às baixas votações dos presidentes do período 1945-1964.

${ }^{7}$ Art. 29, inciso II - eleição do Prefeito e do Vice-Prefeito realizada no primeiro domingo de outubro do ano anterior ao término do mandato dos que devam suceder, aplicadas as regras do art.77 no caso de Municípios com mais de duzentos mil eleitores.

Art. 77, inciso $3^{\circ}$ - Se nenhum candidato alcançar maioria absoluta na primeira votação, far-se-á nova eleição em até vinte dias após a proclamação do resultado, concorrendo os dois candidatos mais votados e considerandose eleito aquele que obtiver a maioria dos votos válidos.

Art. 77, inciso $4^{\circ}$ - Se, antes de realizado o segundo turno, ocorrer morte, desistência ou impedimento legal de candidato, convocar-se-á, dentre os remanescentes, o de maior votação.

Art. 77, inciso $5^{\mathbf{0}}$ - Se, na hipótese dos parágrafos anteriores, remanescer, em segundo lugar, mais de um candidato com a mesma votação, qualificar-se-á o mais idoso. Constituição da República Federativa do Brasil.

${ }^{8}$ Art. $3^{\circ}$ Será considerado eleito Prefeito o candidato que obtiver a maioria dos votos, não computados os em branco e os nulos.

Art. $3^{\circ}$, inciso $1^{\circ}$ - A eleição do Prefeito importará a do candidato a Vice-Prefeito com ele registrado.

Art. $3^{\circ}$, inciso $2^{\circ}$ - Nos Municípios com mais de duzentos mil eleitores, aplicar-se-ão as regras estabelecidas nos incisos $1^{\circ}$ a $3^{\circ}$ do artigo anterior. Lei $\mathbf{n}^{\circ} \mathbf{9 . 5 0 4}$, de 30 de setembro de 1997 .

As condições postas no artigo $2^{\circ}$ da Lei das Eleições são idênticas aos itens do artigo 77 da Constituição Federal visto na nota anterior.
} 
O valor preditivo da segunda lei de Duverger tem razões para ser questionado quanto à efetiva multiplicação de concorrentes. Gary Cox (1997) já indicava uma falha na segunda lei de Duverger, em Majority Runoff, confrontando a visão de que o fator psicológico, ou voto estratégico, seria improvável em condições mais flexíveis proporcionada pela necessidade da maioria absoluta de votos válidos para ser escolhido o vencedor. A afirmação de que o eleitor, podendo escolher quem quisesse no primeiro turno, seria menos suscetível a alterar sua preferência original, precisava ser testada empiricamente.

No estudo de Cox (1997), os eleitores continuam utilizando o voto útil/voto estratégico para colocar na segunda rodada o candidato mais "forte" daquele que é sua preferência prévia. Por exemplo, na medida em que o eleitor tem uma inclinação por um candidato de esquerda, porém as pesquisas de opinião apontam que dois candidatos de direita estariam passando para o segundo turno, termina com o medo do eleitor desperdiçar seu voto. Assim, ele retira o voto da sua opção preferencial na corrida eleitoral para o candidato de esquerda com mais chances de passar para um segundo turno (COX, 1997; DOWNS, 1999; MARENCO, 2012). Isso pode explicar a razão de um número elevado de casos de dualismo de forças em Majority Runoff.

Segundo o modelo de voto estratégico de Cox (1997), os eleitores desertam do seu candidato preferencial a partir da sua colocação nas pesquisas eleitorais. Enquanto em Plurality os votantes abandonam o candidato posicionado em terceiro, restando aos dois primeiros a única vaga em disputa, em Majority Runoff os votantes abandonam o candidato posicionado em quarto lugar em diante. Sempre tendo em mente um eleitor racional, na medida em que seu candidato está na quarta colocação, às expectativas de acesso ao segundo turno tornam-se reduzidas. Desse modo, os eleitores racionais alternam sua preferência para sua segunda escolha sub-ótima na competição eleitoral que esteja mais bem colocado para ir ao segundo turno. O ponto de vista que cerca a análise de Cox (1997) é de que o eleitor quer vencer a eleição a qualquer custo. Além disso, as informações sobre o status da corrida ao Executivo municipal devem estar amplamente disponíveis para a população.

Agora irei testar o fator da reeleição. Esta variável de controle estava fora do modelo teórico de Duverger (1970). Presumo que exista a possibilidade da presença do Incumbent (variável independente) produzir efeitos reducionistas na competição eleitoral (variável dependente) devido às vantagens do cargo de Prefeito: ser uma figura reconhecida do público, ter acesso aos recursos estatais, etc.

Os resultados da tabela 4 apontam que temos $2 \%$ de diferença na competição entre Bicandidaturas conforme a ausência ou a presença de um candidato à reeleição e uma 
diferença igual de 2\% nos casos de Multicandidaturas. Isto mostra que a hipótese de que a participação do Incumbent (candidato a reeleição) na disputa eleitoral modificaria o número de competidores foi refutada. A significância estatística dessa relação apresentou diferenças percentuais ínfimas nos dois casos, bicandidaturas e multicandidaturas, principalmente se comparadas à análise anterior acerca da fórmula eleitoral. A presença do titular do Executivo buscando a reeleição, por si só, não afeta a competição eleitoral.

Tabela 4 - Competição eleitoral nos municípios brasileiros em 2012 conforme a presença de

\begin{tabular}{c|c|c}
\multicolumn{3}{c}{ Incumbents (\%) } \\
\hline \hline \multirow{2}{*}{ Competição Eleitoral } & \multicolumn{2}{|c}{ INCUMBENT } \\
\cline { 2 - 3 } & SIM & NÃO \\
\hline Bicandidaturas & 86 & 16 \\
\hline Multicandidaturas & 14 & -3185 \\
\hline Total & -2371 & \\
\hline \hline
\end{tabular}

Fonte: TSE, dados processados pelo autor. $\mathrm{N}=5556$.

A última tabela desta pesquisa refere-se à possibilidade da presença do Incumbent (variável independente) associada à fórmula eleitoral (variável independente) produzir efeitos na competição eleitoral (variável dependente). Procuro testar o valor associativo destas variáveis explicativas em conjunto, já que separadamente elas atuam de maneira distinta. Nos dados que veremos a seguir, existe uma diferença muito superficial na competição em Plurality, quando há a presença ou ausência do Incumbent em bicandidaturas e isso quase não se altera para os casos de multicandidaturas, em que a diferença chega a ser, inclusive, negativa $(-2 \%)$. Assim, concluo que não há uma associação de variáveis independentes positiva em municípios que utilizem a fórmula de Plurality, o que atinge a maioria das cidades no Brasil.

No entanto, sobre a competição em Majority Runoff a presença de um candidato buscando a reeleição produz uma diferença de $23 \%$ nos casos de bicandidaturas, ou seja, uma regular tendência a diminuição de competidores, enquanto em multicandidaturas aparece uma diferença similar de $23 \%$ sobre a hipótese da ausência do Incumbent produzir aumento de competidores. Percebe-se, então, uma interação entre as variáveis visto que a Lei 
de Duverger, em Majority Runoff, é mais forte quando o Incumbent está ausente. Esta relação, todavia, necessita ser aprofundada em estudos posteriores.

Tabela 5 - Competição eleitoral nos municípios brasileiros em 2012 através da fórmula eleitoral conforme a presença de Incumbents (\%)

\begin{tabular}{c|c|c|c|c}
\hline \hline \multirow{2}{*}{ Competição Eleitoral } & \multicolumn{2}{|c|}{ Plurality } & \multicolumn{2}{c}{ Majority Runoff } \\
\cline { 2 - 5 } & INCUMBENT & AUSENTE & INCUMBENT & AUSENTE \\
\hline Bicandidaturas & 86 & 84 & 57 & 34 \\
\hline Multicandidaturas & 14 & 16 & 43 & 66 \\
\hline Total & -2338 & -3135 & -33 & -50 \\
\hline \hline
\end{tabular}

Fonte: TSE, dados processados pelo autor. $\mathrm{N}=5556$

\section{CONSIDERAÇÕES FINAIS}

Este estudo propôs-se ao entendimento das condições que possibilitam a permanência da tão criticada democracia representativa. A pesquisa mostrou-se também importante para ampliar, em certa medida, o entendimento das reduzidas expectativas de vitória numa disputa eleitoral com regras que reduzem o número de candidatos efetivos. A informação da fórmula eleitoral utilizada nas disputas locais é um bom indicativo da dificuldade que um candidato irá enfrentar na campanha eleitoral.

Apesar do número de municípios com possibilidade de segundo turno ser inferior aos das cidades com turno único, a fórmula de Majority Runofff (maioria absoluta) ainda apresenta maiores oportunidades de sucesso para o lançamento de candidaturas. Esse é um dado que às vezes passa despercebido logo que partidos continuam lançando candidatos em condições mais desfavoráveis, ou seja, em municípios com Plurality, sem atentar para os efeitos do sistema eleitoral. Os resultados indicaram uma forte relação da primeira lei de Duverger sobre a fórmula eleitoral de Plurality em turno único tender para Bicandidaturas, e uma razoável relação da lei de Duverger acerca da fórmula eleitoral de Majority Runoff tender ao aumento dos candidatos efetivos na competição eleitoral.

Esse estudo comparativo da fórmula eleitoral nos municípios brasileiros reforçou a validade de testar teorias mais abrangentes para compreensão de casos locais. Interessava verificar o quanto da produção teórica estrangeira resiste a refutações quando aplicada em casos com trajetórias distintas da europeia como são os partidos brasileiros e da América Latina. Mostrou-se nesta pesquisa que é preciso refinar as predições da teoria tradicional europeia já que ela não se aplica inteiramente para o caso nacional. Conforme visto anteriormente, as hipóteses da fórmula eleitoral de Plurality tender para um dualismo e da 
fórmula eleitoral de Majority Runoff tender para um aumento na competição pareceram válidas contrastadas com nosso objeto de análise. A causalidade encontrada, com forte tendência nas disputas em Plurality, reforça a importância das proposições de Duverger para o entendimento da competição política nacional. $O$ fator da reeleição, inserido na pesquisa como variável de controle, não acarretou em grandes alterações na competição política municipal.

A discussão em voga sobre a necessidade de uma reforma política ampla no Brasil, gerada pelos constantes casos de corrupção no país, mostra a necessidade de discussão acerca das debilidades, e também, dos ganhos que as regras eleitorais que vigoram atualmente no país ocasionam para a estabilidade democrática. Mudanças nas regras do jogo poderiam implicar em desvios nocivos da institucionalização democrática já que a incerteza paira sobre o futuro das instituições políticas advindas de uma drástica reforma política. Os resultados em Plurality apontam uma grande tendência de redução da competição pela ação dos fatores mecânicos e psicológicos pressionando o eleitor a recorrer ao voto estratégico/útil. A classe política e os proponentes de uma reforma política, estes últimos agentes da sociedade civil ou da opinião pública, tem na extinção da fórmula de Majority Runoff (maioria absoluta), mais permissiva para o lançamento de candidaturas, uma arma na redução dos partidos políticos. Consiste, como tarefa futura, averiguar se existe interesse nessa medida pelos atores políticos que contestam o sistema eleitoral atual.

\section{REFERÊNCIAS}

ARENAS, J; VALENCIA, G. 2009. Elecciones y reelecciones presidenciales en América Latina. Perfil de Coyuntura Económica, núm.13, agosto, p. 77-96.

BARRETO, Á. 2014. Destinos Cruzados: Partidos e Candidatos nas Eleições para Prefeito no Brasil e Intendente no Uruguai (2000-2012). Revista Debates, Porto Alegre, v.8, p. 105-125, Jan.-Abr.

COX, G. 1997. Making Votes Count: Strategic Coordination in the World's Electoral Systems. Cambridge: Cambridge University Press.

CARDARELLO, A. 2009. La Reelección inmediata del ejecutivo a nivel subnacional: Un estudio de tres casos. Tese de Doutorado em Ciência Política. Porto Alegre: Programa de Pós-Graduação em Ciência Política UFRGS.

COLOMER, J. 2003. Son los partidos los que eligen los sistemas electorales (o las leyes de Duverger cabeza abajo). Revista Española de Ciencia Política. Núm 9, Octubre, p.39-63. 
CONCEIÇÃO, B. 2014. Competição Eleitoral no Brasil: Análise da influência da fórmula eleitoral nas disputas majoritárias municipais (2008-2012). Dissertação de Mestrado em Ciência Política. Porto Alegre: Programa de Pós-Graduação em Ciência Política UFRGS.

DOWNS, A. 1999. Uma Teoria Econômica da Democracia. São Paulo: Edusp.

DUVERGER, M. 1970. Os Partidos Politicos. Rio de Janeiro: Editora Zahar.

DUVERGER, M. 2003. Duverger's Law: Forty years later. In: GROFMAN, B; LIJPHART, A. Electoral Laws and their Political Consequences. New York: Agathon Press.

LIJPHART, A. 2008. Modelos de Democracia: desempenho e padrões de governo em 36 países. Rio de Janeiro: Ed. Civilização Brasileira.

LIMA JR, O. 1997. O Sistema Partidário Brasileiro. Rio de Janeiro: Editora Fundação Getúlio Vargas.

MAINWARING, S. 2001. Sistemas Partidários em novas democracias - o caso do Brasil. Rio de Janeiro: Editora FGV.

MARENCO, A. 2012. Reformas Eleitorais na América Latina: grandes expectativas, poucos casos, resultados perversos. Sociologias, Porto Alegre, ano 14, n³1, set/dez. p.238-268.

NICOLAU, J. 1996. Multipartidarismo e Democracia: um estudo sobre o sistema partidário brasileiro. Rio de Janeiro: Editora FGV.

NOHLEN, D. 1995. Sistemas electorales y partidos políticos. México: Fondo de Cultura Económica.

SCHUMPETER, J. 1961. Capitalismo, Socialismo e Democracia. Rio de Janeiro: Editora Fundo de Cultura.

SHUGART, M; CAREY, J. 1992. Presidents and Assemblies: Constitutional Design and Electoral Dynamics. Cambridge: Cambridge University Press.

TAVARES, J. 1997. Rio Grande do Sul: o sistema partidário eleitoral e parlamentar. In: LIMA JR, Olavo Brasil de. O Sistema Partidário Brasileiro. Rio de Janeiro: Editora FGV. 